\title{
Novel Eco-Friendly Techniques for Extraction of Food Based Lipophilic Compounds from Biological Materials
}

\author{
Kate $\mathrm{AE}^{1 *}$, Anupama Singh ${ }^{2}$, Shahi $\mathrm{NC}^{2}$, Pandey $\mathrm{JP}^{2}$, Om Prakash ${ }^{3}$ and Singh $\mathrm{TP}^{4}$
}

${ }^{1} A P P D$, ICAR-Central Institute of Agricultural Engineering, Bhopal, Madhya Pradesh, India

${ }^{2}$ Department of Postharvest Process and Food Engineering, College of Technology, GB Pant University of Agriculture and Technology, Pantnagar, Uttarakhand, India

${ }^{3}$ Department of Chemistry, College of Basic Sciences and Humanities, GB Pant University of Agriculture and Technology, Pantnagar, Uttarakhand, India

${ }^{4}$ Department of Farm Machinery and Power Engineering, College of Technology, GB Pant University of Agriculture and Technology, Pantnagar, Uttarakhand, India

\begin{abstract}
Plant-based lipophilic compounds such as edible oils, phytochemicals, flavors, fragrances and colours are valuable products in the food, pharmaceutical and chemical industry. Extraction is one of the key processing steps in recovering and purifying lipophilic ingredients contained in plant- based materials. Lipophilic compounds are found in the cells of oil bearing plant seeds. Solvent extraction is the most common commercially used extraction method for low oil content materials. Solvent extraction has more extractability than existing commercial methods, but it also passes serious limitations and environmental issues. The Environmental Protection Agency has been much concerned regarding safety and environmental emissions associated with hexane usage in the solvent extraction process. Bio-solvents resulting from renewable raw materials and in particular from the biomass may become a solution of the existing problem. But the existing conventional extraction methods cannot respond to such solvent and hence need for new novel "Green" extraction technology having potential to overcome all limitations of existing technologies. This review will discuss the various possible novel eco-friendly extraction methods, their scientific concepts, principles, challenges, limitations and technological effort needed for successful implementation at the production scale.
\end{abstract}

Keywords: Extraction; Green extraction; Lipophilic compounds; Novel technology

\section{Introduction}

Naturally obtained bioactive compounds such as edible oils, phytochemicals, flavors, fragrances and colors are gaining much interest in food and cosmetic industries because of their therapeutic effect over synthetic ones. These compounds are having negligible side effects as compared to synthetically prepared. Edible oil is the highest used compound among the all in the whole world. India is the highest consumer of edible oil worldwide, and its demand goes on increasing steadily. India's consumption of edible oil has risen to around 17.5 million MT in 2012-2013 from 11.6 million MT in 2003-04. The country had produced 8.0 million MT of edible oil during 2013-14. India has become the largest importer of edible oil as a country had imported around 11.8 million MT (about 60\% of total need) during 2013-14 [1]. The demand for both edible and non-edible oils is increasing due to different contributing factors like rising income, growing population and expanding urbanization. As a result, there is an overall decline in the per capita availability of edible oils [2]. Hence the nation's dependency on imported oil is expected to reach alarming levels up to $60-65 \%$ up to 2050 [1].

India is the largest producer of oilseeds but still deficient as far as production of oil is concerned. The need per head per day is $30 \mathrm{~g}$ oil for an adult human being to meet the minimal dietary requirement whereas, at present, the availability is only $11 \mathrm{~g}$ per head per day per adult human being. The largest source of oil at present is the seeds of annual plants such as groundnut, soybean, mustard/rapeseed, sunflower etc. There are as many as 100 different types of oilseed bearing plants in the forest and mountains of India and out of them only a dozen species have been exploited for oil extraction.

Extraction is one of the key processing steps in recovering and purifying lipophilic ingredients contained in plant-based materials [3]. An oil body is a unit of storage lipophilic compounds called lipids and is found in the cells of oil bearing plant seeds used for oil consumption such as peanut, soybean, and olive seeds. Oil bodies (OB) are surrounded by a single layer of phospholipids as membrane, and are stable both in the cell and in isolated preparations. The most abundant oil body-associated with proteins called oleosin. Oleosins in seeds are small proteins of about 15-26 k Da. They completely cover the surface of the subcellular oil bodies. They can be abundant in seeds with a high proportion of oils and small OBs (therefore large total OB surface area). Hundreds of genes encoding oleosins have been identified in diverse plant species, ranging from higher to primitive plants [4]. This indicated that storage oil droplets surrounded by a phospholipids monolayer acquire their illusion coat to keep stable [5]. Hence, by using the appropriate extraction technology and processing conditions, it is possible to simultaneously integrate oil and protein extraction as protein is also a main nutritional constitute of food and feed.

Many extraction methods have been employed to extract oil from plant seeds. The traditional plant oil extraction methods include expeller pressing or mechanical pressing and organic solvent extraction. Mechanical pressing are used for high oil content $(>22 \%$ dry basis) [6] and becomes simpler process for extraction, but passes some limitation and disadvantages like low extractability, labor-intensive, high energy consumption and has high level initial equipment cost, chemical structure changes due to colloidal structure damage and residual oil in the cake. Solvent extraction is the most commonly used commercially used extraction methods for the seeds bearing low oil content $(<20 \%$ dry basis) materials [6]. Solvent extraction has more extractability than explore pressing but it also passes serious limitations like the plant security problems, residual solvent, high effluent disposal, emission of volatiles in an environment and time consuming process (few hours to some days). Worldwide, in solvent extraction plants, $\mathrm{n}$ hexane is the most frequent used solvent for extraction of fatty acids,

*Corresponding author: Kate AE, APPD, ICAR-Central Institute of Agricultural Engineering, Bhopal, Madhya Pradesh, India, E-mail: kateadinath@gmail.com

Received June 10, 2016; Accepted July 01, 2016; Published July 07, 2016

Citation: Kate AE, Singh A, Shahi NC, Pandey JP, Prakash O, et al. (2016) Novel Eco-Friendly Techniques for Extraction of Food Based Lipophilic Compounds from Biological Materials. Nat Prod Chem Res 4: 231. doi:10.4172/2329-6836.1000231

Copyright: ( $) 2016$ Kate AE, et al. This is an open-access article distributed under the terms of the Creative Commons Attribution License, which permits unrestricted use, distribution, and reproduction in any medium, provided the original author and source are credited. 
while other traditional solvents generally volatile organic compounds, harmful to health and the environment. Indeed, they contribute to the troposphere ozone formation and the contamination of water and soil. The Environmental Protection Agency has been much concerned regarding safety and environmental emissions associated with hexane usage and issued restrictive regulations on hexane uses and emissions [7]. This is why environmental regulations oblige the industries to use alternative (substitute) solvents. In this context, bio-solvents resulting from renewable raw materials and in particular from the biomass became an exact solution of the problem [8]. But the conventional extraction methods cannot respond to such solvent and hence need for new novel "Green" extraction technology with shortened extraction time, low investment, reduced solvent consumption, energy efficient, increased pollution prevention, and with special care for thermo labile constituents.

The alcohols are used as a solvent for replacement of conventional petroleum solvents during solid-liquid extraction of lipophilic compounds. However, these alternative solvents often result in less recovery during conventional extraction process. Hence alternative novel methods are used with alternative solvent. The various novel extraction techniques have become relatively mature, and some potential applications for the extraction.

However, little research has been done so far on the establishment of novel green technique for plant oil extraction. There are various novel technologies for extraction of lipophilic compounds at laboratory scale which includes Supercritical Fluid extraction (SFE), Ultrasound assisted extraction (UAE), Ohmic heating assisted extraction (OHAE), Pulsed electric extraction (PEE), pressurized liquid extraction (PLE), Microwave assisted extraction (MAE) etc. Each type of method has a specific area of application.

Still, today there is not that much technical research has been done worldwide in novel extraction techniques. Hence, there is a great need to improve the understanding of extraction mechanism, to remove technical barriers, to improve the design and scale up of the novel extraction systems for better industrial applications.

\section{Methodology}

The various limitations of traditional extraction methods are longer extraction time, requirement of costly and high purity petroleum solvent, loss of the huge amount of solvent in the environment, lower selectivity of solute and thermal degradation of thermo-sensitive compounds [9]. To overcome these limitations of commercially used conventional extraction methods, novel bio-solvent based extraction techniques are introduced. These techniques are referred as sustainable, eco-friendly extraction techniques. Some of the potential promising techniques for extraction of plant based lipophilic compounds are ultrasound assisted extraction, enzyme-assisted extraction, microwaveassisted extraction; pulsed electric field assisted extraction, supercritical fluid extraction and pressurized liquid extraction. These techniques are also identified as "green techniques" as they comply with standards set by the Environmental Protection Agency. These standards include less hazardous chemical synthesis; safer chemicals, safe polar and nonpolar solvents with auxiliaries, energy efficiency, complete utilization of feedstock, reduce derivatives, catalysis, degradation free process, sustainability of the sensitive compound, and processing time for pollution prevention and inherently safer chemistry for the prevention of accidents.

\section{Ultrasound-assisted extraction (UAE)}

Ultrasound is basically sound wave with the frequency of $20 \mathrm{kHz}$ to $100 \mathrm{MHz}$, which is beyond the audible range of human hearing. Power ultrasounds are used for carrying out the various processes and chemical reactions. Power ultrasound uses, frequencies, normally in the range of $20-100 \mathrm{kHz}$ (generally less than $1 \mathrm{MHz}$ ), and can produce much higher power levels, in the order of $10-1000 \mathrm{Wcm}^{-2}$. This low frequency, high power ultrasound has sufficient energy to break intermolecular bonds, and energy intensities greater than $10 \mathrm{Wcm}^{-2}$ will generate cavitation effects, which are known to alter some physical properties as well as enhance or modify many chemical reactions. When ultrasound waves pass through a medium they involve expansion and compression cycles. Expansion pulls molecules apart and compression pushes them together. These mechanisms create bubbles in a liquid which can grow and finally collapse, such phenomenon is called cavitation. During cavitation bubbles collapse near the surface of the cell wall and produces temperatures up to $5000 \mathrm{~K}$ and pressure up to $1000 \mathrm{ATM}$. UAE has been developed on this principle of cavitation's.

The mechanical effects of ultrasound created by cavitation induce a greater penetration of the solvent into cellular materials and improve mass transfer. Ultrasound in extraction can also disrupt biological cell walls, facilitating the release of contents. Therefore, efficient cell disruption and effective mass transfer are two key factors which leading to the enhancement of extraction with ultrasonic power [10]. Chemat et al. provided evidence of the mechanical effects of ultrasound, mainly shown by the destruction of cell walls and release of cell contents [11]. In contrast to conventional extractions, plant extracts diffuse across cell walls due to ultrasound, causing cell rupture over a shorter period $[12,13]$.

The extraction by ultrasound should pass through two main steps, firstly the diffusion across the cell wall and secondly rinsing the contents of cell after breaking the walls. The various parameters like moisture content of sample, raw material preparation, particle size of feed stock and solvent type (i.e., Polar or non-polar) are the important variables which affect the severity of extraction. Additionally, temperature, pressure, frequency and time of sonication can also be the factors for the action of ultrasound. UAE can also be combined with conventional extraction techniques, increasing the efficiency of the existing extraction method successfully. In a solvent extraction unit, an ultrasound device is can be used as a pretreatment to enhance the extraction efficiency [14]. The main advantages of UAE are: reduced extraction time (only a few minutes of treatment), efficient energy and solvent use (polar/ bio-solvent), more effective mixing, faster energy transfer, reduced extraction temperature and degradation, selective extraction, reduced equipment size, faster response to process, quick start-up, increased production and eliminates process steps [15]. It has been reported that ultrasound can improve the extraction yield depending on the type of solvent and its interaction with the solute.

The use of ultrasound-assisted extraction is advisable for thermo labile compounds, which may be altered under Soxhlet operating conditions due to the high extraction temperature [16]. However, it should be noted that since ultrasound generates heat, it is important to accurately control the extraction temperature [17]. The sonication time should also be considered carefully as an excess of sonication can damage the quality of extracts. According to Herrera et al. [18] UAE can be successfully used in solid plant sample because ultrasound energy facilitates organic and inorganic phenolic compounds leaching from plant matrix.

Yang et al. [19] applied optimized sonication condition to extract bioactive compounds called rutin and quercetin from Euonymus alatus (Thund.). $\mathrm{Zu}$ et al. were extracted phenol carboxylic acids, carnosic acid and rosmarinic acid from Rosmarinus officinalis using Ionic liquid based UAE technique which was proved to have high efficiency and shorter extraction time than conventional extraction methods [20]. 
Therefore, it found that ultra-sonication was a critical pretreatment to obtain high yields of oils and other lipophilic compounds. The yield of oil extracted from soybeans also increased significantly using ultrasound [21]. For ultrasound-assisted extraction of saponin from ginseng, the observed total yield and saponin yield increased by 15 and $30 \%$, respectively [22]. Cravotto et al. found that rice bran oil extraction can be efficiently performed in 30 min under high-intensity ultrasound either using hexane or a basic aqueous solution [23]. Extraction rates of carvone and limonene by ultrasound-assisted extraction with hexane were 1.3-2 times more rapid than those by the conventional extraction depending on temperature [11]. So it concludes that UAE can increase extraction kinetics as well as improves the quality of extracts.

\section{Pulsed-electric field extraction (PEF)}

This is one of the important non-thermal emerging extraction technique. In PEF, during processing food is placed between two electrodes and exposed to a pulsed high voltage field (typically $20-80 \mathrm{kV}$ $\mathrm{cm}^{-1}$ ) for the treatment times in order of less than $1 \mathrm{~s}$, at multiple short duration pulses typically less than $5 \mu$ s. The principle behind pulsed electric field extraction is that it ruptures cell membrane structure and changes the semipermeable nature of the cell wall to partially permeable by formation of small holes called electro pore and process called "electroporation" which helps to release the lipophilic component of the cell membrane to the solvent. In the PEF process an electric potential passes through the membrane of that cell which is in suspension of raw material and solvent. Electric potential separates molecules according to their charge in the cell membrane depending on the dipole nature of membrane molecules. A drastic increase of permeability is caused after exceeding a critical value of approximately $1 \mathrm{~V}$ of trans membrane potential as repulsion occurs between the charge carrying molecules that form pores in weak areas of the membrane and causes the flow of inside material of cell to outer low pressure environment [24]. This phenomenon of PEF treatment can effectively utilize for extraction of lipophilic compounds from its source materials.

According to the mechanism explained by Zimmermann [25,26], during pulse electric treatment the cell membrane can be considered to be a capacitor that is filled with a cell matrix acts as dielectric material. The normal resisting potential difference across the membrane (the trans membrane potential) is around $10 \mathrm{mv}$. If an external electric field is applied, this increases the potential difference across the cell membrane. This increase in potential difference causes a reduction in the membrane thickness. When the potential difference across the cell reaches a critical level (normally considered to be around $1 \mathrm{~V}$ ), pores are formed in the membrane. This leads to an immediate discharge at the membrane pore and, consequently, membrane damage [25]. Breakdown of the membrane is reversible only if the pores are small in relation to the total membrane surface, but when pores are formed across large areas of the membrane then permanent destruction of the cell wall results. This is the birth of "electroporation".

During some of the laboratory experiments, a simple circuit with exponential decay pulses is used for PEF treatment of plant materials. It consists of a treatment chamber with two electrodes where plant materials are placed. Depending on the design of treatment chamber and scale of the process PEF extraction can be either continuous or batch process [27]. There are various constructional, electrical and material factors may effect on the performance of the process. Ref. [28] reported that the efficiency of PEF treatment rigorously depends on the process parameters likewise electric field strength, specific energy input, pulse number, treatment temperature and type of raw materials.
PEF has become one of the promising techniques for extraction of lipophilic compounds during organic synthesis as, PEF increases the rate of mass transfer during extraction by the disturbing membrane structure of cell wall for enhancing extraction yield and decreasing extraction time. Increase in yield at a reduced extraction time is mainly because of, PEF can improve release of intracellular compounds from plant tissue with the help of increasing cell membrane permeability created by the electroporation [29]. PEF treatment at a moderate electric field (500 and $1000 \mathrm{~V} / \mathrm{cm}$ and for $10^{-4}$ to $10^{-2} \mathrm{~s}$ ) can damage cell membrane of plant tissue with only little temperature increase [30,31]. Due to this reason, PEF is identified as non-thermal extraction technique and can be successfully used for heat sensitive compounds [32]. Similarly like ultrasound PEF can also be applied on plant materials as a pretreatment process prior to conventional extraction or utilized as independent PEF assisted leaching based extraction.

As the non-thermal in nature PEF was applied for extraction of thermo sensitive lipophilic compounds. Guderjan et al. [33] reported that the recovery of phytosterols from maize increased by $32.4 \%$ and isoflavonoids (genistein and daidzein) from soybeans increased by $20-21 \%$ when PEF was used as a pretreatment process before conventional extraction. Ref. [34] extracted bioactive compound such as anthocyanins from grape by-product using PEF and found increased extraction yield. The permeabilization of Merlot skin by a pulsed electric field treatment resulted in increased extraction of polyphenols and anthocyanins [35].

\section{Enzyme-assisted extraction (EAE)}

Enzymatic pre-treatment has been considered as an effective way to release bounded compounds inside the cell wall and increase overall yield. Lipophilic compounds in the biological materials, mainly present in the plant matrices and are dispersed in cell cytoplasm retained by hydrogen or hydrophobic bonding, so cannot be easily assessable to the solvent in a routine extraction process. The addition of specific enzymes like cellulase, a-amylase, and pectinase during extraction enhances recovery by partial breaking the cell wall and hydrolyzing the structural polysaccharides and lipid bodies [36,37] changes the semipermeable nature of the cell wall. The extent of the change depends upon the type of the enzyme and reaction conditions maintained. Use of polar solvent like water is the main advantage of this method over all other advanced novel extraction methods. Enzyme-assisted extraction may performed by enzyme-assisted aqueous extraction (EAAE) or enzymeassisted cold pressing (EACP) [38]. Usually, EAAE methods have been developed mainly for the extraction of lipophilic compounds, i.e., Oils from various seeds as it has significant density difference in density of extraction compound and water $[36,39,40]$.

In EACP technique, enzymes are used to hydrolyze the seed cell wall, because in this system polysaccharide-protein colloid is not available, which is obvious in EAAE [41]. There are various factors which effects on the process like type of enzyme, concentration and composition of enzyme, particle size of source materials, solvent to solute ratio, reaction temperature and incubation time [42]. Dominguez et al. found out that the moisture content of plant based source materials is also an important factor for enzymatic hydrolysis [43]. Bhattacharjee et al. described EACP as an ideal alternate for extracting bioactive components from oilseed, because of its nontoxic, eco-friendly and noninflammable properties unlike to conventional solvent extraction process [44]. The Enzyme Assisted Extraction might be recognized as eco-friendly technology for extraction of bioactive compounds and plat based lipophilic compounds because it uses water as solvent instead of conventional organic petroleum based chemicals. But there is need 
for advancement of downstream processes carried out for refinement of EAE compounds as the compounds extracted by enzyme- assisted methods were found in the form of emulsion with the solvent as well as other bioactive compounds presents inside the cells which is highly complex and difficult for separation of desired product [43].

Laboratory level work was going on from last decade in area of standardization and optimization of EAE of bioactive compounds. Ref. [45] extracted total phenolic contents from five citrus peels (Yen Ben lemon, Meyer lemon, grapefruit, mandarin and orange) by EAAE using different enzymes and the recovery was highest with celluzyme MX enzyme. Considerable improvements have been recently achieved in enzyme assisted aqueous extraction, processing of extruded soybean flakes [46,47] and soybean flour [48] but still not satisfactory achievement was getting. While the most advanced EACP for extracting extruded soybean flakes with the aid of a protease enzyme in a countercurrent two-stage strategy resulted in higher oil extraction yield of $99 \%$ as an extrusion process broken the cell wall which enhances the reaction rate of protease, an unstable emulsion obtained during the process was easily demulsified by adjusting the $\mathrm{pH}$ of the emulsion to the isoelectric point of the soy proteins $(4.5)[19,47,49]$. During EAE it produced a soluble protein fraction (skim) containing around $20 \%$ of the total oil and other lipophilic compounds that were very difficult to isolate due to the extensive hydrolysis used to free oil [50]. On the other hand, while the EAE of oilseeds $6+$ flour like soybean resulted in lower oil extraction yield and the formation of stable emulsions. Although effective extraction of oil and other lipophilic compounds from AEPs/ EAEPs is desirable, the easy and economically viable recovery of free oil and isolate from emulsion and skim fractions, respectively, is essential. Likewise the Pulse electric field extraction EAE also a non-thermal extraction technique.

\section{Microwave assisted extraction (MAE)}

The microwave-assisted extraction is also a novel method for extracting lipophilic products using microwave energy. Microwaves are electromagnetic fields in the frequency range from $300 \mathrm{MHz}$ to 300 GHz. They are made up of two oscillating fields such as electric field and magnetic field that are perpendicular to each other. Microwaves are transmitted as waves, which can penetrate biomaterials and interact with polar molecules such as water in the biomaterials to create heat. Consequently, microwaves can heat a whole material to penetration depth simultaneously. Electromagnetic energy is converted to heat following ionic conduction and dipole rotation mechanisms [51]. During the ionic conduction mechanism heat is generated because of the resistance of medium to flow ion. On the other hand, ions keep their direction along field signs which change frequently. This frequent change of directions results in a collision and friction between molecules and consequently generates heat. This collision and friction of dipole molecule ruptures the cell wall and cell matrix is open up for interaction with the solvent medium. So MAE has become the fastest method of extraction.

During extraction series of phenomenological steps must occur during the period of interaction between the solid-containing particle and the solvent effectuating the separation, including (1) penetration of the solvent into the solid matrix; (2) solubilization and/or breakdown of components; (3) transport of the solute out of the solid matrix; (4) migration of the extracted solute from the external surface of the solid into the bulk solution; (5) movement of the extract with respect to the solid; and (6) separation and discharge of the extract and solid.

Therefore, the solvent penetrates into the solid matrix by diffusion (effective), and the solute is dissolved until reaching a concentration limited by the characteristics of the solid. The solution containing the solute diffuses to the surface by effective diffusion. Finally, by natural or forced convection, the solution is transferred from the surface of the bulk solution.

In MAE, the process acceleration and high extraction yield may be the result of a synergistic combination of two transport phenomena: heat and mass gradients working in the same direction [52]. On the other hand, in conventional extractions the mass transfer occurs from inside to the outside, although the heat transfer occurs from the outside to the inside of the substrate. In addition, although in conventional extraction the heat is transferred from the heating medium to the interior of the sample, in MAE the heat is dissipated volumetrically inside the irradiated medium.

There are several advantages of MAE such as (1) reduced extraction time (2) reduced solvent usage and (3) improved extraction yield (4) quicker heating of stock material (5) reduced thermal gradient and reduced equipment size. MAE is also comparable to other modern extraction techniques such as supercritical fluid extraction due to its process simplicity and low cost. By considering economical and practical aspects, MAE is a strong novel extraction technique for the extraction of bioactive compounds. It is a selective technique to extract organic and organometallic compounds that are more intact. MAE is also recognized as a green technology because it reduces the use of organic solvent [53].

Guo et al. conducted an experiment for MAE of the puerarin from the herb Radix puerariae and it was found that extraction could be completed within $1 \mathrm{~min}$ [54]. MAE with $80 \%$ methanol as a solvent could dramatically reduce the extraction time of ginseng saponins from $12 \mathrm{~h}$ using conventional extraction methods to a few seconds [55]. MAE was taken only $30 \mathrm{~s}$ to extract cocaine from the leaves with quantitatively similar yield those obtained by conventional solvent extraction for several hours [56]. In the extraction experiments of tanshinones from Salvia miltiorrhizabunge, MAE needed only $2 \mathrm{~min}$, whereas extraction at room temperature, Soxhlet extraction, ultrasonic extraction, and heat reflux extraction needed $24 \mathrm{~h}, 90,75$ and $45 \mathrm{~min}$ [57]. During various experiments, it was found that the presence of water in the any non-polar organic/inorganic solvent had a beneficial effect and allowed faster extractions than with solvent alone.

\section{Pressurized liquid extraction (PLE)}

Pressurized liquid extraction (PLE) which is now known by several names: pressurized fluid extraction (PFE), accelerated fluid extraction (ASE), enhanced solvent extraction (ESE), and high pressure solvent extraction (HSPE) [58]. In this technique of extraction, high pressure in the range of 10 to $15 \mathrm{Mpa}$ is applied over the solvent in contact with source materials. This elevated pressure increases the temperature as well as boiling point of solvent simultaneously, which causes reduction in viscosity of solute and solvent present in that environment. Due to elevated pressure, reduced viscosity and higher temperature enhance the permeability of cell walls, hence extraction cell to be filled faster and helps to force liquid solvent into the solid matrix. Elevated temperatures and reduced viscosity enhance diffusivity of the solvent and solute resulting in increased extraction kinetics. The concept of PLE is to increase the boiling point of the solvent by application of high pressure and remain solvent in liquid state throughout the process at higher temperature more than the boiling of that solvent at STP. Introduction and advancement of artificial intelligence based automation techniques during the last few decades are the main reason greater development of PLE-based techniques along with the decreased extraction time and solvents requirement. PLE method provides a higher extraction 
yield, lower extraction time with only small amounts of solvents because of the combination of high pressure, high temperatures and low viscosity. Reason behind this extraction kinetics is: elevated extraction temperature can promote higher solubility of solute by increasing both solubility and mass transfer rate. Also decrease in the viscosity and surface tension of solvents improves rate of extraction rate [59]. In comparison to the conventional solvent extraction PLE decrease extraction process time and quantity of solvent [60]. PLE can also be given the desirable response to the polar solvents as they're lower soluble with non-polar compounds are counterbalanced by elevated pressure and temperature and because of that PLE becomes a potential alternative technique for supercritical fluid extraction [61]. Requirement of small amounts of organic solvent in PLE gives it broad reorganization as a green extraction technique [59]. Rostagno et al. were extracted isoflavones from soybeans (freeze-dried) at optimized conditions of pressure and temperature without degradation by PLE [62]. In consideration of yield, reproducibility, extraction time, and solvent consumption, PLE has been considered as an alternate to conventional methods due to faster process and lower solvent use. Luthria [63] showed temperature, pressure, particle size, flush volume, static time, and solid-to-solvent ratio parameters have influence on the extraction of phenolic compounds from parsley (Petroselinum crispum) flakes by PLE. During optimized PLE of lycorine and galanthamine (Amaryllidaceae alkaloids) from Narcissus jonquilla, it was found that, optimized PLE method was more effective than hot-solvent extraction, MAE, and UAE [64].

\section{Supercritical fluid extraction (SFE)}

This is the most popular technique for extraction of thermo sensitive bioactive compounds. The application of supercritical fluid for extraction purposes started with its discovery by Hannay and Hogarth. Since this beginning, supercritical fluid technique was successfully used in environmental, pharmaceutical and polymer applications and food analysis [65]. Every substance has three basic states, namely; Solid, Liquid and Gas. Supercritical state is a distinctive state and can only be found if a substance is subjected to temperature and pressure beyond its critical point. The Critical point is defined as the characteristic temperature (Tc) and pressure (Pc) above which distinctive gas and liquid phases do not exist [66]. In supercritical state, the specific properties of gas or liquid become vanish, which means supercritical fluid cannot be liquefied by modifying temperature and pressure. Supercritical fluid possesses gas-like properties of diffusion, viscosity, and surface tension, and liquid-like density and solvation power. These properties make it suitable for extracting compounds in a short time with higher yields [67]. Carbon dioxide is considered as an ideal solvent for SFE. The critical temperature of $\mathrm{CO}_{2}$ is close to room temperature, and the low critical pressure ( 74 bars) offers the possibility to operate at moderate pressures, generally between 100 and 450 bars. Additionally, it has low polarity which makes it ideal for lipid, fat and non-polar substance in which most lipophilic compounds belongs. The major variables influencing the extraction efficiency are temperature, pressure, particle size and moisture content of feed material, time of extraction, flow rate of $\mathrm{CO}_{2}$, and solvent-to-feed-ratio [66]. The advantages of using supercritical fluids for the extraction can be: (1) higher diffusion coefficient and lower viscosity and surface tension than liquid solvent, causing more penetration to sample and increased mass transfer, reduced Extraction time, complete extraction, ecofriendly, higher selectivity than liquid solvent. SFE operates at room temperature, so it can be used for heat sensitive materials. In SFE, small amount of sample can be extracted compared with solvent extraction methods which will save time for overall experiment. The recycling and reuse of supercritical fluid is possible and thus minimizing waste generation and operating cost. Besides these due to the high initial investment on equipment's and instrumentations faces problem for popularization at commercial level [68].

\section{Future challenges in novel extraction technology research}

Although a superiority of the new novel extraction techniques over existing conventional technologies their scale up at the commercial level becomes far ahead from the success. However, most of these novel extraction techniques are still conducted successfully in the laboratory and small batch-scale level, although few techniques like supercritical fluid extraction and ultrasound as a pre-treatment can be found in several industrial applications. Still today laboratory results are mainly concentrated on extracting extra-cellular compounds like essential oils, phenolic and terpenoid compounds. But the no potential laboratory research was done regarding extraction of intra-cellular lipophilic compound where destruction of the cell wall is must for extraction $[69,70]$.

Novel extraction processes are complex thermodynamic systems with higher capital costs. To maintain the sustainability, effectiveness and minimum capital cost with due consideration of complex thermodynamic and mass transfer processes faces the challenges for engineering design of novel extraction systems. Knowledge of transport phenomenological and mass transfer properties of various solutes, solvents and a variety of raw materials becomes key constraints for engineering and process design so it calls for precise instrumentation of the process. Modeling of novel extraction processes can provide a better understanding of the insight into the extraction mechanisms and be used to quickly optimize extraction conditions and scale-up any design.

\section{Technical barriers of novel extraction techniques}

In ultrasound assisted extraction formation of restricted zone for waves located in the vicinity of the emitter so careful consideration of ultrasound power range and capacity during design of ultrasoundassisted extractors are needed. Microwave assisted extraction is one of the superior technology and famous for its dramatic abrupt reduction in extraction time and increased extraction yield at minimum amount of solvent. This happens due to high temperature and homogeneous temperature distribution over penetration depth reached by microwave heating. But MAE gives very poor results when either the target compounds or the solvents are non-polar, or when they are volatile. In case of MAE of intracellular lipophilic compounds it is difficult to extract and separates single target compounds. Furthermore, many thermo sensitive bioactive compounds may degrade during extraction. More research is needed to investigate the interaction between microwaves, and plant materials and solvents.

Supercritical fluid extraction is one of the most accepted and successful novel technique at industrial level. However, in supercritical fluid extraction, $\mathrm{CO}_{2}$ is exclusively used as the extracting solvent, but it is restricted to non-polar extracts. Supplementation of the other techniques like Accelerated solvent extraction to SFE can be removes the barriers presents in the extraction of polar compounds. More research is needed to reduce the capital and operating costs of SFE.

\section{Conclusions}

The demand and need to extract lipophilic compounds from plant based sources continued searching for economically and ecologically feasible sustainable extraction technologies. Traditional solid-liquid extraction methods require a large quantity of solvent and are time 
consuming. The large amount of solvent used not only increases operating costs, but also causes additional environmental problems. So there is a severe requirement of sustainable, green extraction technologies which overcomes the all circumstances and disadvantages of existing methods with possible response to the bio-solvents. Novel extraction techniques have been developed as an alternative to conventional extraction methods, offering advantages like low extraction time, minimized consumption of solvent, high extraction yields and low operating cost. More research is needed to improve the understanding of extraction mechanism, remove technical barriers, improve the design and scale up of the novel extraction systems for their industrial applications.

\section{References}

1. Industry (2015) India's oilseed production should be linked to food security. The Hindu, Accessed on 13 January 2015.

2. Kumar JG, Suresh P, Mathur VC, Bisaria G, Anbukkani P, et al. (2012) Edible Oilseeds Supply and Demand Scenario in India: Implications for Policy. Division of agricultural economics, IARI, pp: 1-30

3. Liu W (1999) Oil processing technology and equipment. Beijing, China. Chinese Economic Publication.

4. Tzen JT, Huang AH (1992) Surface structure and properties of plant seed oil bodies. J Cell Biol 117: 327-335.

5. Frandsen GI, Mundy J, Tzen JT (2001) Oil bodies and their associated proteins, oleosin and caleosin. Physiol Plant 112: 301-307.

6. Uquiche E, Jerez M, Ortiz J (2008) Effect of pretreatment with microwaves on mechanical extraction yield and quality of vegetable oil from Chilean hazelnuts. Innovative Food Science and Emerging Technologies 9: 495-500.

7. Environmental Protection Agency (2001) 40 CFR Part 63, National emissions standards for hazardous air pollutants: solvent extraction for vegetable oil production, final rule. Federal Register 66: 19005-19026. Accessed on March 2015.

8. Bertouche S, Tomao V, Hellal A, Boutekedjiret C, Chemat F (2013) Firs approach on edible oil determination in oilseeds products using alpha-pinene Journal of Essential Oil Research 25: 439-443.

9. Luque de Castro MD, Garcia-Ayuso LE (1998) Soxhlet extraction of solid materials: an outdated technique with a promising innovative future. Analytica Chimica Acta 369: 1-10.

10. Mason TJ, Paniwnyk L, Lorimer JP (1996) The uses of ultrasound in food technology. Ultrasonics Sonochemistry 3: 253-260.

11. Chemat S, Lagha A, AitAmar H, Bartels PV, Chemat F (2004) Comparison of conventional and ultrasound-assisted extraction of carvone and limonene from caraway seeds. Flavour and Fragrance Journal 19: 188-195.

12. Toma M, Vinatoru M, Paniwnyk L, Mason TJ (2001) Investigation of the effects of ultrasound on vegetal tissues during solvent extraction. Ultrason Sonochem 8: 137-142.

13. Vinatoru M, Toma M, Mason TJ (1999) Ultrasound-assisted extraction of bioactive principles from plants and their constituents. Advances in Sonochemistry 5: 209-247.

14. Vinatoru M, Toma M, Filip P, Achim T, Stan N, et al. (1998) Ultrasonic Reactor Dedicated to the Extraction of Active Principles from Plants. Romanian Patent $\mathrm{Nr}$ 98-01014

15. Chemat F, Tomao V, Virot M (2008) Handbook of Food Analysis Instruments. Ultrasound-Assisted Extraction in Food Analysis. In: Otles S (ed), CRC Press, pp: 85-94.

16. Romdhane M, Gourdon C (2002) Investigation in solid-liquid extraction: Influence of ultrasound. Chemical Engineering Journal 87: 11-19.

17. Salisová M, Toma S, Mason TJ (1997) Comparison of conventional and ultrasonically assisted extractions of pharmaceutically active compounds from Salvia officinalis. Ultrason Sonochem 4: 131-134.

18. Herrera MC, Luque de Castro MD (2005) Ultrasound-assisted extraction of phenolic compounds from strawberries prior to liquid chromatographic separation and photodiode array ultraviolet detection. Journal of Chromatography 1100: 1-7.
19. Yang $Y$, Zhang $F$ (2008) Ultrasound-assisted extraction of rutin and quercetin from Euonymus alatus (Thunb.) Sieb. Ultrason Sonochem 15: 308-313.

20. Zu G, Zhang R, Yang L, Ma C, Zu Y, et al. (2012) Ultrasoundassisted extraction of carnosic acid and rosmarinic acid using ionic liquid solution from Rosmarinus officinalis. International Journal of Molecular Science 13: 11027-11043.

21. Li H, Pordesimo L, Weiss J (2004) High intensity ultrasound assisted extraction of oil from soybeans. Food Research International 37: 731-738.

22. Hui L, Etsuzo O, Masao I (1994) Effects of ultrasound on the extraction of saponin from ginseng. Japanese Journal of Applied Physics 33: 3085-3087.

23. Cravotto G, Binello A, Merizzi G, Avogadro M (2004) Improving solvent-free extraction of policosanol from rice bran by high-intensity ultrasound treatment. European Journal of Lipid Science and Technology 106: 147-151.

24. Bryant G, Wolfe $J$ (1987) Electromechanical stress produced in the plasma membranes of suspended cells by applied electrical fields. Journal of Membrane Biology 96: 129-139.

25. Barbosa-Canovas GV, Pierson MD, Zhang QH, Schaffner DW (2000) Pulsed Electric Fields. J Food Sci Suppl, pp: 65-79.

26. Jeyamkondan S, Jayas DS, Holley RA (1999) Pulsed electric field processing of foods: a review. J Food Prot 62: 1088-1096.

27. Puertolas E, Lopez N, Saldana G, Alvarez I, Raso J (2010) Evaluation of phenolic extraction during fermentation of red grapes treated by a continuous pulsed electric fields process at pilot-plant scale. Journal of Food Engineering 119: $1063-1070$

28. Heinz V, Toepfl S, Knorr D (2003) Impact of temperature on lethality and energy efficiency of apple juice pasteurization by pulsed electric fields treatment Innovative Food Science and Emerging Technologies 4: 167-175.

29. Toepfl S, Mathys A, Heinz V, Knorr D (2006) Review: potential of high hydrostatic pressure and pulsed electric fields for energy efficiency and environmentally friendly food processing. Food Review International 22: 405-423.

30. Fincan M, Dejmek P (2002) In situ visualization of the effect of a pulsed electric field on plant tissue. Journal of Food Engineering 55: 223-230.

31. Lebovka NI, Bazhal MI, Vorobiev E (2002) Estimation of characteristic damage time of food materials in pulsed-electric fields. Journal of Food Engineering 54 337-346.

32. Ade-Omowaye BIO, Angersbach A, Taiwo KA, Knorr D (2001) Use of pulsed electric field pre-treatment to improve dehydration characteristics of plant based foods. Trends in Food Science and Technology 12: 285-295.

33. Guderjan M, Töpfl S, Angersbach A, Knorr D (2005) Impact of pulsed electric field treatment on the recovery and quality of plant oils. Journal of Food Engineering 67: 281-287

34. Corralesa M, Toepflb S, Butza P, Knorrc D, Tauschera B (2008) Extraction of anthocyanins from grape by-products assisted by ultrasonics, high hydrostatic pressure or pulsed electric fields: a comparison. Innovative Food Science and Emerging Technologies 9: 85-91.

35. Delsart C, Ghidossi R, Poupot C, Cholet C, Grimi N, et al. (2012) Enhanced extraction of phenolic compounds from merlot grapes by pulsed electric field treatment. American Journal of Enology and Viticulture 63: 205-211.

36. Rosenthal A, Pyle DL, Niranjan K (1996) Aqueous and enzymatic processes for edible oil extraction. Enzyme Microbial Technology 19: 402-420.

37. Singh RK, Sarker BC, Kumbhar BK, Agrawal YC, Kulshreshtha MK (1999) Response surface analysis of enzyme-assisted oil extraction factors for sesame, groundnut, and sunflower seeds. Journal of Food Science and Technology 36: 511-514.

38. Latif S, Anwar F (2009) Physicochemical studies of hemp (Cannabis sativa) seed oil using enzyme-assisted cold-pressing. European Journal of Lipid Science and Technology 111: 1042-1048.

39. Hanmoungjai P, Pyle DL, Niranjan K (2001) Enzymatic process for extracting oil and protein from rice bran. Journal of the American Oil Chemists Society 78: 817-821.

40. Sharma A, Khare SK, Gupta MN (2002) Enzyme-assisted aqueous extraction of peanut oil. Journal of American Oil Chemist's Society 79: 215-218.

41. Concha J, Soto C, Chamy R, Zuniga ME (2004) Enzymatic pretreatment on Rose-Hip oil extraction: hydrolysis and pressing conditions. Journal of American Oil Chemist's Society 81: 549-552. 
Citation: Kate AE, Singh A, Shahi NC, Pandey JP, Prakash O, et al. (2016) Novel Eco-Friendly Techniques for Extraction of Food Based Lipophilic Compounds from Biological Materials. Nat Prod Chem Res 4: 231. doi:10.4172/2329-6836.1000231

42. Niranjan K, Hanmoungjai $P$ (2004) Enzyme-aided aquous extraction. In Dunford NT, Dunford, HB (eds.) Nutritionally Enhanced Edible Oil Processing. AOCS Publishing.

43. Dominguez H, Ntiiiez MJ, Lema JM (1995) Enzyme-assisted hexane extraction of soybean oil. Food Chemistry 54: 223-231.

44. Bhattacharjee P, Singhal RS, Tiwari SR (2006) Supercritical carbon dioxide extraction of cottonseed oil. Journal of Food Engineering 79: 892-989.

45. Li BB, Smith B, Hossain MM (2006) Extraction of phenolics from citrus peels: II. Enzyme-assisted extraction method. Separation and Purification Technology 48: 189-196.

46. De Moura JMLN, Maurer D, Jung S, Johnson LA(2011) Pilot-plant proof-of- concept for integrated, countercurrent, two-stage, enzyme-assisted aqueous extraction of soybeans. Journal of the American Oil Chemists Society 88: 1649-1658.

47. De Moura JMLN, De Almeida NM, Johnson LA (2009) Scale-up of enzymeassisted aqueous extraction processing of soybeans. Journal of the American Oil Chemists Society 86: 809-815

48. Chabrand RM, Glatz CE (2009) Destabilization of the emulsion formed during the enzyme-assisted aqueous extraction of oil from soybean flour. Enzyme and Microbial Technology 45: 28-35.

49. Jung S, Maurer D, Johnson LA (2009) Factors affecting emulsion stability and quality of oil recovered from enzyme-assisted aqueous extraction of soybeans. Bioresour Technol 100: 5340-5347.

50. Campbell KA, Glatz CE, Johnson LA, Jung S, De Moura JMN, et al. (2011) Advances in aqueous extraction processing of soybeans. Journal of the American Oil Chemists Society 88: 449-465

51. Jain T, Jain V, Pandey R, Vyas A, Shukla SS (2009) Microwave assisted extraction for phytoconstituents - an overview. Asian Journal of Research in Chemistry 2: 19-25.

52. Chemat F, Abert-Vian M, Zill-e-Huma Y-J (2009) Microwave assisted separations: green chemistry in action. In: Pearlman JT (eds.). Green Chemistry Research Trends. Nova Science Publishers, New York, USA, pp: 33-62.

53. Alupului A (2012) Microwave extraction of active principles from medicinal plants. UPB Science Bulletin Series B, p: 74

54. Guo Z, Jin Q, Fan G, Duan Y, Qin C, et al. (2001) Microwave-assisted extraction of effective constituents from a Chinese herbal medicine Radix puerariae. Analytica Chimica Acta 436: 41-47.

55. Kwon JH, Belanger JMR, Jocelyn Pare JR, Yaylayan VA (2003) Application of microwave-assisted process (MAP TM) to the fast extraction of Ginseng saponins. Food Research International 36: 491-498.

56. Brachet A, Christen P, Veuthey JL (2002) Focused microwave-assisted extraction of cocaine and benzoylecgonine from coca leaves. Phytochem Anal 13: $162-169$.
57. Pan X, Niu G, Liu H (2002) Comparison of microwaveassisted extraction and conventional extraction techniques for the extraction of tanshinones from Salvia miltiorrhizabunge. Biochemical Engineering Journal 12: 71-77.

58. Nieto A, Borrull F, Pocurull E, Marcé RM (2010) Pressurized liquid extraction: a useful technique to extract pharmaceuticals and personal-care products from sewage sludge. Trends in Analytical Chemistry 29: 752-764.

59. Ibañez E, Herrero M, Mendiola JA, Castro-Puyana M (2012) Extraction and characterization of bioactive compounds with health benefits from marine resources: macro and micro algae, cyanobacteria, and invertebrates. In Hayes M (ed), Marine Bioactive Compounds: Sources, Characterization and Applications. Springer, pp: 55-98.

60. Richter BE, Jones BA, Ezzell JL, Porter NL, Avdalovic N, et al. (1996) Accelerated solvent extraction: a technology for sample preparation. Analytical Chemistry 68: 1033-1039.

61. Kaufmann B, Christen P (2002) Recent extraction techniques for natural products: microwave-assisted extraction and pressurized solvent extraction. Phytochemical Analysis 13: 105-113.

62. Rostagno MA, Palma M, Barroso CG (2004) Pressurized liquid extraction of isoflavones from soybeans. Analytica Chimica Acta 522: 169-177.

63. Luthria DL (2008) Influence of experimental conditions on the extraction of phenolic compounds from parsley (Petroselinum crispum) flakes using a pressurized liquid extractor. Food Chemistry 107: 745-752.

64. Mroczek T, Mazurek J (2009)Pressurized liquid extraction and anticholinesterase activity- based thin-layer chromatography with bioautography of Amaryllidaceae alkaloids. Analytica Chimica Acta 633: 188-196.

65. Zougagh M, Valcárcel M, Ríos A (2004) Supercritical fluid extraction: a critical review of its analytical usefulness. Trends in Analytical Chemistry 23: 399-405.

66. Inczedy J, Lengyel T, Ure AM (1998) Supercritical Fluid Chromatography and Extraction. Compendium of Analytical Nomenclature. Definitive Rules 1997 3rd edn., Blackwell Science.

67. Sihvonen M, Jarvenpaa E, Hietaniemi V, Huopalahti R (1999) Advances in supercritical carbon dioxide technologies. Trends in Food Science and Technology 10: 217-222.

68. De Moura JN, Johnson LA (2009) Two-stage countercurrent enzyme-assisted aqueous extraction processing of oil and protein from soybeans. Journal of the American Oil Chemists Society 86: 283-289.

69. Rosenthal A, Pyle DL, Niranjan K, Gilmour S, Trinca L (2001) Combined effect of operational variables and enzyme activity on aqueous enzymatic extraction of oil and protein from soybean. Enzyme and Microbial Technology 28: 499-509.

70. Wu J, Johnson LA, Jung S (2009) Demulsification of oil-rich emulsion from enzyme- assisted aqueous extraction of extruded soybean flakes. Bioresource Technology 100: 527-533. 